\title{
Um olhar alteritário em Bakhtin: o estudo do enunciado como forma de diálogo
}

\author{
Simone Mussio ${ }^{1}$ \\ UNESP/FCLAr - FATEC JAHU
}

Resumo: Sendo o princípio fundante da teoria dialógica do discurso a filosofia do diálogo, a qual concebe o homem não como um ser individual, mas como aquele que se constitui através da relação dialógica entre um eu e um tu, todo enunciado, segundo esta concepção teórica, passa a ser dialógico por natureza. Como o dialogismo é tido como a ordem do enunciado, este não se fecha em si, mas é constituído através do infindável diálogo entre enunciados outros que o precedem ou o sucedem na cadeia discursiva. Desse modo, partindo desta alteridade presente na constituição discursiva, este trabalho tem como objetivo, a partir de uma exposição literária sobre o assunto, tendo nas particularidades do conceito de enunciado, ancorado nos gêneros do discurso, a gênese de uma teoria enunciativa que, pautada nas condições de enunciação e nos interlocutores envolvidos, assegura ao enunciado uma univocidade histórica determinada pelos contextos de interação verbais específicos. Para isso, são retratadas as críticas de Bakhtin com relação às duas orientações centrais do pensamento filosófico-linguístico, o subjetivismo idealista e o objetivismo abstrato, bem como a diferenciação entre os conceitos de "palavra" e "oração", para, por fim, travarmos um diálogo sobre as fronteiras do enunciado concreto, o qual é tido como elemento chave da comunicação verbal.

Palavras-chave: Enunciação. Teoria dialógica do discurso. Bakhtin. Dialogismo.

\section{Introdução}

Como a teoria a ser explanada neste trabalho pauta-se nos pressupostos e pensamentos bakhtinianos da linguagem, é importante frisar que a concepção dialógica traz o outro como ponto central dos seus dizeres, pois, uma vez que a própria vida é dialógica por natureza, “a alteridade define o ser humano, pois o outro é indispensável para sua concepção: é impossível pensar no homem fora das relações que o ligam ao outro" (BAKHTIN apud BRAIT, 1997, p. 35-36). Como o dialogismo é constitutivo da linguagem, mesmo nas produções ditas monológicas, é possível perceber a presença de relações dialógicas, fazendo com que todo gênero seja dialógico por natureza.

Assim, a teoria bakhtiniana concebe como importantes as vozes sociais que engendram os discursos, a vida e, consequentemente, o próprio ser humano. Logo, é através de tais vozes

\footnotetext{
${ }^{1}$ Docente titular na Faculdade de Tecnologia de Jahu; Doutoranda em Linguística e Língua Portuguesa pela Universidade Estadual Paulista de Araraquara; Mestre em Comunicação pela Universidade Estadual Paulista de Bauru; e Graduada em Português-Espanhol pela Universidade Federal de São Carlos. 
que os enunciados são tecidos, constituídos, ecoados e reverberados no dialogar das inúmeras ações humanas, haja vista que "todos os fenômenos presentes na comunicação real podem ser analisados à luz das relações dialógicas que os constituem” (FIORIN, 2006, p. 27).

Desse modo, este trabalho tenciona, sob uma metodologia qualitativa, com análise interpretativa do pensamento bakthtiniano, fazer ecoar os preceitos de Bakhtin e seu Círculo, tendo como ênfase a constituição do conceito enunciado, através da teoria dialógica do discurso, de maneira a demonstrar como esta dá início à urdidura de sua teoria da enunciação ao confrontar duas orientações centrais do pensamento filosófico-linguístico: o subjetivismo idealista e o objetivismo abstrato. Em seguida, ainda tendo como foco a questão do enunciado, buscamos diferenciar tal conceito dos termos "palavra" e "oração", de modo a retomarmos a discussão de como se dão as fronteiras do enunciado concreto, o qual é visto como o principal elemento da comunicação verbal.

Como o enunciado é visto como a unidade real da comunicação discursiva, e todas as esferas da atividade humana se relacionam com o uso da língua - evidenciado em forma de enunciados (orais e escritos) concretos e singulares -, o enunciado passa a refletir situações específicas, a partir de um determinado gênero discursivo. Por isso, para Bakhtin, aprender a falar quer dizer aprender a construir enunciados, afinal, falamos através deles, e não através de orações. É assim que os gêneros funcionam como suporte aos enunciados, organizando a nossa fala, da mesma maneira que as formas gramaticais sintáticas a sistematizam.

Posto isso, a partir deste diálogo com os preceitos bakhtinianos, tendo como ponto fulcral o estudo do enunciado, pretendemos, assim, colaborar com a disseminação desta teoria dialógica do discurso, a qual pode proporcionar frutíferas reflexões e análises para os estudos enunciativos.

\section{Enunciar é preciso... Posicionar-se também!}

Quando Bakhtin (2010) assevera que a linguagem só pode ser analisada segundo sua devida complexidade, ou seja, através dos fenômenos socioideológicos apreendidos dialogicamente no fluxo da história, ele claramente demarca sua posição enunciativa ao conceber as enunciações proferidas (e vividas) pelos seres humanos como fruto dos vínculos existentes da linguagem com a vida e com a história. Desse modo, a concepção de linguagem de Bakhtin (2006) é arquitetada a partir de uma crítica radical às grandes correntes da Linguística de sua época, por considerar que tais teorias não trabalhavam a língua como fenômeno social. 
Bakhtin e seu Círculo fazem, então, uma crítica epistemológica às duas grandes correntes linguísticas, as quais foram denominadas de Objetivismo Abstrato e Subjetivismo Idealista. Para eles, o objeto de estudo de cada uma dessas correntes tinha um objetivo reducionista. A primeira por reduzir a língua a um sistema abstrato de normas, e a segunda por ver a língua como expressão da realidade interna, reduzida à enunciação monológica isolada (prioriza o aspecto interior, o lado subjetivo da criação significativa). O Círculo, no entanto, prediz que o verdadeiro núcleo da realidade linguística consiste na prática viva da língua. Em razão de entender a linguagem nessa dimensão, sua teoria aponta que a língua é inseparável do fluxo da comunicação verbal e, por conseguinte, não é transmitida como um produto acabado, mas como algo que se constitui continuamente na corrente da comunicação verbal, pois

A verdadeira substância da língua não é constituída por um sistema abstrato de formas linguísticas nem pela enunciação monológica isolada, nem pelo ato psicológico de sua produção, mas pelo fenômeno da interação verbal, realizada através da enunciação ou das enunciações. A interação verbal constitui assim a realidade fundamental da língua (BAKHTIN, 2006, p. $125)$.

Bakhtin, desse modo, se opõe a ambas as correntes de pensamento e acrescenta a enunciação como parte integrante da atividade linguística. É a partir deste ponto que o teórico institui a noção de enunciação como processo histórico não reiterável em que as formas linguísticas somam forças em prol de um evento de fala que abarca bem mais do que a língua em si, enquanto sistema, e um sujeito falante individualizado em um ato ${ }^{2}$ criativo, mas, sim, as condições de produção daquele enunciado, os interlocutores encetados naquela interação verbal, assim como o caráter social da própria atividade linguística.

Bem além de um sistema inerte ou pautando-se só (e somente) em um produto de atos criativos individuais, a língua deve ser vista como uma atividade evolutiva e incessante que se perfaz à medida que é utilizada em situações reais de fala.

$\mathrm{Na}$ realidade, o locutor serve-se da língua para suas necessidades enunciativas concretas (para o locutor, a construção da língua está orientada no sentido da enunciação da fala). Trata-se, para ele, de utilizar as formas normativas [...] num dado contexto concreto (BAKHTIN, 2006, p. 93-94).

Assim, o termo enunciação é entendido pela teoria bakhtiniana como sendo a unidade real da linguagem (expressão linguística), logo, o produto dessa expressão verbal caracteriza-

\footnotetext{
${ }^{2}$ Segundo Bakhtin (2010), cada pensamento, associado a um conteúdo, pode ser considerado um ato ou uma ação realizada, sendo, portanto, uma ação ou um ato individualmente responsável. Este, por sua vez, ainda de acordo com o autor, é um de todos aqueles atos que fazem da vida um realizar ininterrupto de atos, já que a vida pode ser considerada como um complexo ato (ou ação singular) realizada singularmente pelos indivíduos. 
se pelo enunciado. Bakhtin (2010) declara, então, que a linguagem é um fenômeno de duas faces, já que presume sempre a existência de um falante e de um ouvinte - ainda que este não seja real.

A interação entre os interlocutores é o princípio fundador da linguagem e se cumpre por intermédio do diálogo entre ouvinte e falante, mediado pela palavra, "modo mais puro e sensível de relação social” (BAKHTIN, 2006, p. 34). Por essa razão, é baseando-nos em pressupostos teóricos desse autor, que pretendemos elucidar como a enunciação é construída ao diferenciá-la, a seguir, dos vocábulos (unidades da língua) "palavra" e "oração".

\section{Entre palavras e orações: dois nomes, duas medidas}

A palavra, bem como a oração pura e simples, não requer ato comunicativo, não suscita uma atitude de resposta por parte do outro, pode ser retirada do contexto, possui uma conclusibilidade abstrata, logo, pode não ser precisa; funciona como elemento, não como um todo. A oração em si não tem autoria, e só a partir do momento em que se torna um enunciado, em uma situação discursiva, é que passa a representar a intenção do falante. No entanto, as palavras são definidas de acordo com as especificidades do gênero discursivo a ser utilizado. Já que o gênero é uma forma típica do enunciado, no gênero a palavra incorpora esta tipicidade:

\footnotetext{
A oração enquanto tal, em seu contexto, não tem capacidade de determinar uma resposta; adquire essa propriedade (mais exatamente: participa dela) apenas no todo de um enunciado. A oração que se torna enunciado completo adquire novas qualidades e particularidades que não pertencem à oração, mas ao enunciado, que não expressam a natureza da oração, mas do enunciado e que, achando-se associadas à oração, completam-na até torná-la um enunciado completo. (...) As pessoas não trocam orações, assim como não trocam palavras (numa acepção rigorosamente linguística), ou combinações de palavras, trocam enunciados constituídos com a ajuda de unidades da língua - palavras, combinações de palavras, orações; mesmo assim, nada impede que o enunciado seja constituído de uma única oração, ou de uma única palavra, por assim dizer, de uma única unidade da fala (o que acontece sobretudo na réplica do diálogo), mas não é isso que converterá uma unidade da língua numa unidade da comunicação verbal (BAKHTIN, 1997, p. 297).
}

Bakhtin considera que a palavra não é dotada apenas de expressão típica, mas também de expressão individual, já que nos comunicamos por meio de enunciações individuais. À diferença do enunciado, palavra e oração são desassistidas de "endereçamento"; não são, assim, ditas para alguém, não pertencem e nem se referem a ninguém, eximem-se de qualquer tipo de relação com o dizer do outro. 
Já o enunciado, podendo ser escrito ou falado, presume um ato de comunicação social, sendo, desse modo, a unidade real do discurso. Neste processo, existe uma interatividade entre sujeitos. O "receptor" não é um ser passivo, mas, ao ouvir e compreender um enunciado, adota para consigo uma atitude responsiva, podendo discutir, direcionar, ampliar, concordar ou não com que está sendo "dito", atuando de forma ativa no ato enunciativo. O locutor também não deseja uma reação passiva, mas um retorno, uma vez que age no sentido de provocar uma resposta, intervém sobre o outro buscando tocá-lo, convencê-lo, influenciá-lo. Bakhtin salienta que esta atitude é a principal característica do enunciado. Logo, este não pode ser repetido (apenas citado), já que se deriva de discursos proferidos no exato momento da interação social.

Para a teoria bakhtiniana, o enunciado é resultante de uma "memória discursiva" acondicionado de enunciados que já foram proferidos em outras épocas, em outras situações interacionais, nas quais o locutor, inconscientemente, toma como base para realizar a enunciação do momento, para formular seu discurso. Bakhtin (1997) questiona, assim, os termos "ouvinte" e "receptor" pela linguística tradicional, uma vez que tais acepções representam uma imagem totalmente distorcida do processo complexo da comunicação verbal, pois quando buscam representar o todo real do processo comunicativo, o receptor adota também uma atitude responsiva perante o que está sendo proferido, não agindo passivamente. Nas palavras do autor:

De fato, o ouvinte que recebe e compreende a significação (linguística) de um discurso adota simultaneamente, para com este discurso, uma atitude responsiva ativa: ele concorda ou discorda (total ou parcialmente), completa, adapta, apronta-se para executar, etc., e esta atitude do ouvinte está em elaboração constante durante todo o processo de audição e de compreensão desde o início do discurso, às vezes já nas primeiras palavras emitidas pelo locutor (BAKHTIN, 1997, p. 290).

A compreensão de uma fala disposta em enunciado vivo é apoiada em uma atitude responsiva ${ }^{3}$ ativa, partindo do pressuposto de que toda compreensão é também prenhe de resposta, forçando o ouvinte, de alguma forma, torna-se, direta ou indiretamente, locutor. Todavia, essa compreensão responsiva ativa pode se realizar por meio de uma fala, de um ato, de uma ação, mas pode também permanecer uma compreensão responsiva muda

\footnotetext{
${ }^{3}$ Segundo os pressupostos bakhtinianos, a atitude do interlocutor é sempre uma atitude responsiva ainda que não se traduza imediatamente em nenhum ato ou discurso. Assim, o conceito de enunciação, segundo Bakhtin/Voloshinov (2006, p. 126), é visto como "um puro produto da interação social, quer se trate de um ato de fala determinado pela situação imediata ou pelo contexto mais amplo que constitui o conjunto das condições de vida de uma determinada comunidade linguística". Logo, uma palavra, uma frase ou até uma sequência de frases instituem a enunciação que, vista como uma réplica do diálogo social, promove a interação entre os sujeitos. Contudo, essa palavra, ou grupo de palavras, só se firma como um enunciado quando se estabelece como signo ideológico.
} 
(compreensão responsiva de ação retardada), pois cedo ou tarde, tudo aquilo que foi ouvido, lido ou visto será compreendido de maneira ativada e encontrará um eco no discurso ou no comportamento daquele ouvinte.

De acordo com Bakhtin, os gêneros secundários da comunicação verbal ${ }^{4}$, em sua maior parte, contam precisamente com esse tipo de compreensão responsiva de ação retardada, valendo-se tanto para o discurso lido, como também escrito. Logo,

A compreensão responsiva nada mais é senão a fase inicial e preparatória para uma resposta (seja qual for a forma de sua realização). O locutor postula esta compreensão responsiva ativa: o que ele espera, não é uma compreensão passiva que, por assim dizer, apenas duplicaria seu pensamento no espírito do outro, o que espera é uma resposta, uma concordância, uma adesão, uma objeção, uma execução, etc. (...). O próprio locutor como tal é, em certo grau, um respondente, pois não é o primeiro locutor, que rompe pela primeira vez o eterno silêncio de um mundo mudo, e pressupõe não só a existência do sistema da língua que utiliza, mas também a existência dos enunciados anteriores - emanantes dele mesmo ou do outro - aos quais seu próprio enunciado está vinculado por algum tipo de relação (fundamenta-se neles, polemiza com eles), pura e simplesmente ele já os supõe conhecidos do ouvinte (BAKHTIN, 1997, p. 291-292).

Consoante esta teoria, os enunciados - organizados e agrupados - são usados em toda e qualquer atividade humana, sendo essas atividades caracterizadas por condições especiais de atuação e por objetivos específicos comumente associados a elas.

Uma vez que a diversidade de gêneros varia conforme as circunstâncias, o nível social e o relacionamento entre os sujeitos devem ser também levados em conta. Como o sujeito sempre faz uma escolha por um determinado gênero, essa escolha é determinada em função da comunicação verbal que se pretende estabelecer, tendo como referência o seu intuito discursivo e a própria constituição dos seus interlocutores.

Segundo Bakhtin (1997), não há limites para os gêneros, pois eles estão diretamente relacionados com as múltiplas atividades da vida social. Nesse sentido, os gêneros desenvolvem-se em proporção ao desenvolvimento das práticas humanas.

Todavia, voltando-nos à questão do enunciado, é possível observarmos que quaisquer que sejam o volume, o conteúdo ou a composição, os enunciados sempre conservam, como unidades da comunicação verbal, características estruturais que lhes são comuns, e, acima de

\footnotetext{
${ }^{4}$ Dotados de uma imensa heterogeneidade e sem menosprezar qualquer uma de suas variedades, os gêneros do discurso são concebidos por Bakhtin (1997) em gêneros primários e secundários. Os primeiros são, pois, classificados como enunciados utilizados na vida cotidiana, sugerindo, desse modo, uma comunicação, coloquial e imediata, a qual Rodrigues (2005, p. 169) chama "ideologia do cotidiano (as ideologias não formalizadas e sistematizadas)", como as vistas em um bilhete, piada ou em um bate-papo, por exemplo. Já os gêneros secundários, normalmente, surgem em situações comunicativas complexas, considerando culturas com linguagens mais elaboradas, como os textos jurídicos, jornalísticos, religiosos, científicos, etc. 
tudo, fronteiras definidas. Em se tratando das fronteiras enunciativas, passemos agora à questão das idiossincrasias do enunciado.

\section{As fronteiras do enunciado tendo em vista suas particularidades constituintes}

Para uma melhor elucidação das ideias bakhtinianas a serem traçadas, elencaremos, a seguir, os postulados de Bakhtin (1997, p. 294) que, ao retomar a discussão sobre as fronteiras do enunciado concreto, compreendido como uma unidade da comunicação verbal, mostra que tais fronteiras enunciativas são determinadas por questões referentes à (ao):

a) Alternância dos sujeitos falantes, ou seja, pela alternância dos locutores, uma vez que todo enunciado (desde uma réplica monolexemática até um tratado científico) tem um início e um fim absoluto, pois, antes de seu início, já existiam os enunciados dos outros e, depois de seu fim, há ainda os enunciados-respostas dos outros. É importante salientar que essa alternância dos sujeitos falantes que traça fronteiras estritas entre os enunciados nas diversas esferas da atividade e da existência humana é diversamente caracterizada e adota formas variadas. Contudo, essa relação estabelecida entre as réplicas de um diálogo (seja ele direto ou indireto) apenas ocorre durante o processo da comunicação verbal, sendo impossível entre as unidades da língua, ou seja, entre as palavras e orações, uma vez que pressupõe o outro e não se presta a uma gramaticalização ${ }^{5}$, mas ao contexto real do diálogo.

b) Acabamento específico do enunciado. O acabamento do enunciado é, de certa maneira, a alternância dos sujeitos falantes vista do interior. Essa mudança ocorre, precisamente, porque o locutor disse (ou escreveu) o que queria dizer em um momento e em condições precisas. Então, ao ouvir, ler (ou assistir), percebemos o fim de um enunciado, como se ouvíssemos o "dixi” conclusivo do locutor. Este denota um acabamento totalmente específico e que pode ser caracterizado por meio de critérios particulares. O mais importante dos critérios de acabamento de um enunciado é a possibilidade de responder - a adoção de uma atitude responsiva para com ele. Há, por sua vez, três fatores desta conclusibilidade específica: o tratamento do objeto do sentido, o intuito discursivo, o querer-dizer do locutor

\footnotetext{
5 Segundo a teoria na qual nos ancoramos, concebemos o termo "gramaticalização" associado à palavra ou à oração, uma vez que partilhamos o pressuposto de que estas, ao se situarem somente como "unidades da língua", não estando materializadas em um enunciado concreto, não partilham de sentidos outros depreendidos do contexto sócio-histórico.
} 
acoplado às formas do gênero do acabamento. $\mathrm{O}$ primeiro elemento difere em relação aos diversos campos de atividade humana, por exemplo, nos campos, nos quais os gêneros refletem uma natureza padrão, o acabamento é praticamente pleno, ao passo que nos gêneros menos padronizados, pode-se falar só em um acabamento mínimo. O segundo alude à vontade de dizer do sujeito e é através dessa intenção verbalizada que é possível medir a conclusibilidade do enunciado, ou seja, somos capazes de perceber quando o outro finalizou seu turno, para que possamos tomar o nosso. O terceiro fator, o mais importante dos três para Bakhtin, está relacionado à escolha do gênero discursivo pelo sujeito, oriundo de sua intenção comunicativa. Esta escolha é caracterizada em relação à esfera pela qual o discurso transitará, por seu conteúdo temático, pelas condições de produção e pela composição dos participantes. Desse modo, o querer-dizer do locutor se realiza na escolha de um determinado gênero.

c) Relação do enunciado com o próprio locutor e com os outros parceiros da comunicação verbal. Sendo o enunciado o "elo na cadeia da comunicação verbal" (BAKHTIN, 1997, p. 308), ele se caracteriza como conteúdo do objeto de sentido. Num primeiro momento, é a execução desse objeto do sentido que vai determinar a escolha do gênero discursivo apropriado à determinada esfera de comunicação pelo locutor. Logo em seguida, num segundo momento, na etapa da escolha da composição e do estilo, tem-se a necessidade de expressividade do locutor ante o objeto de seu enunciado. A importância e a intensidade dessa fase expressiva diversificam de acordo com as esferas da comunicação verbal, todavia existe em todo tipo de manifestação discursiva, uma vez que um enunciado absolutamente neutro é inexequível.

Assim, para o autor, essa expressividade de sentido e, por conseguinte, a noção de estilo se caracterizam pelo (a):

(1) Princípio expressivo do discurso expresso no enunciado concreto, não na língua enquanto sistema (frases, orações, palavras, etc.), já que é sabido que as palavras não são de ninguém, logo, elas não comportam um juízo de valor.

(2) Expressividade marcada pela relação emotiva-valorativa do locutor com o objeto do discurso, sendo a entonação expressiva utilizada para expressar a relação emotivo-valorativa do locutor com o objeto do seu discurso, de forma a definir o seu estilo individual. Fora do enunciado, essa entonação é inexistente. Assim, se uma palavra isolada é proferida com uma 
entonação expressiva, já não é uma palavra, mas um enunciado completo. "A significação da palavra se refere à realidade efetiva nas condições reais da comunicação verbal" (BAKHTIN, 1997, p. 310).

(3) Significação de uma palavra dentro do enunciado, através dos recursos lexicais, gramaticais do enunciado, pois ao escolher a palavra, guiamo-nos nas intenções que presidem ao todo do nosso enunciado, e não no tom emocional da palavra isolada. "Apenas o contato entre a significação linguística e a realidade concreta, apenas o contato entre a língua e a realidade — que se dá no enunciado - provoca o lampejo da expressividade" (Ibid., p. 310). Selecionamos, assim, uma palavra segundo as características de um determinado gênero, ou seja, pelo seu tema, composição e estilo. Destarte, "as significações lexicográficas das palavras da língua garantem sua utilização comum e a compreensão mútua de todos os usuários da língua, mas a utilização da palavra na comunicação verbal ativa é sempre marcada pela individualidade e pelo contexto" (Ibid., p. 313). A palavra pode, porém, existir para o locutor por meio de três situações: a) como palavra neutra da língua (não pertence a ninguém); b) como palavra do outro (pertencente aos outros e preenche o eco dos enunciados alheios); e c) como palavra minha (no uso de determinada intenção discursiva, o uso de determinada palavra impregna-se da expressividade de quem a utiliza). Assim, nestes dois últimos casos, vemos como a palavra nasce nas circunstâncias de uma situação real, apresentando-se por meio de aglomerados de enunciados (o pai, a mãe, o professor, o cientista, etc.). "As palavras dos outros introduzem sua própria expressividade, seu tom valorativo, que assimilamos, reestruturamos, modificamos" (Ibid., p. 314).

(4) Dialogicidade com outros enunciados. A expressividade não se dá através do locutor com seu objeto do sentido, porque o enunciado estabelece uma relação dialógica com outros enunciados; a expressividade de um enunciado se marca, portanto, por essa relação com outros enunciados:

O enunciado está repleto dos ecos e lembranças de outros enunciados, aos quais está vinculado no interior de uma esfera comum da comunicação verbal. $\mathrm{O}$ enunciado deve ser considerado acima de tudo como uma resposta a enunciados anteriores dentro de uma dada esfera (Ibid., p. 316).

Desse modo, Bakhtin discursa sobre as tonalidades dialógicas que inteiram um enunciado, sendo estas importantes características para a obtenção e compreensão do estilo do enunciado, uma vez que até nosso próprio pensamento nasce no embate ao pensamento alheio, refletindo e refratando as formas de expressão do nosso pensamento. 
(5) Noção de estilo em Bakhtin, ao englobar não somente a questão da expressividade posta na valoração do locutor diante do seu objeto de discurso, mas compreender as tonalidades dialógicas, bem como a relação do locutor com seu interlocutor. Por conseguinte, "o índice substancial (constitutivo) do enunciado é o fato de dirigir-se a alguém, de estar voltado para o destinatário” (Ibid., p. 320). No entanto, este destinatário pode ser de distintas instâncias, desde o interlocutor direto do diálogo até um outro não concretizado determinado pelas distintas áreas da atividade humana. A quem o enunciado é dirigido, a forma como o locutor imagina e percebe o seu destinatário, o modo como o destinatário pode influenciar o enunciado, tudo isso influi na composição e no estilo do enunciado, uma vez que "cada um dos gêneros do discurso, em cada uma das áreas da comunicação verbal, tem sua concepção padrão do destinatário que o determina como gênero" (Ibid., p.321).

(6) Possibilidade de percepção/recepção do interlocutor, fato que determinará a escolha do gênero. O locutor, deste modo, leva em conta como sua fala será recebida pelo destinatário, o grau informacional deste diante da situação, bem como as suas opiniões, convicções, preconceitos, seus conhecimentos, já que tudo isso interferirá na compreensão responsiva do enunciado a ser proferido. Uma vez refletidas tais características, dar-se-á a escolha do gênero do discurso, como também dos recursos linguísticos a serem empregados, compondo, assim, o estilo do seu enunciado. "Vê-se como o estilo depende do modo que o locutor percebe e compreende seu destinatário, e do modo que ele presume uma compreensão responsiva ativa" (Ibid., p. 324). É desse modo que Bakhtin engendra sua crítica à estilística tradicional, a qual não percebe o papel determinante do interlocutor no processo de interação verbal e tenta definir o estilo ancorando-se exclusivamente no conteúdo do discurso, ou seja, no nível do objeto, e na expressiva relação do locutor com tal conteúdo. Já diz Bakhtin "Quando se subestima a relação do locutor com o outro e com seus enunciados (existentes ou presumidos), não se pode compreender nem o gênero nem o estilo de um discurso" (Ibid., p. 324).

(7) Individualidade e coletividade do estilo refletidas nos gêneros. O estilo passa, então, a ser individual e coletivo concomitantemente. Coletivo, pois nos comunicamos sempre a partir de um gênero e este se caracteriza por sua tipicidade (elementos de base determinados por sua permanência), porém, ao mesmo tempo, os gêneros são tidos como enunciados que, como unidades reais de comunicação, são assumidos por falantes, por indivíduos marcados por sua singularidade. Por esse mesmo motivo, Bakhtin propõe uma definição dialógica de estilo, contrariando a frase "O estilo é o homem", de Buffon em "Discours sur le Style", de 
1753, ao proferir que o estilo é pelo menos dois homens, ou seja, uma pessoa e seu grupo social.

O autor, desse modo, atribui o termo "estilo" a algo acoplado aos gêneros do discurso, destaca que por meio dele é que a individualidade do falante/escritor pode ser refletida, todavia, diz que nem sempre é possível ao sujeito representar sua individualidade estilística, pois alguns gêneros exigem uma forma padronizada de linguagem, como, por exemplo, documentos oficiais, artigos científicos, etc. Atenta, também, para o fato de que o estilo caracteriza-se como o "epifenômeno" do enunciado, já que não se escreve com determinado estilo, é o estilo que acaba sendo o produto - consequência do escrito/fala.

Nas palavras de Amorim (2004), ao retratar este conceito bakhtiniano, a autora revela:

O estudo dos estilos só pode ser feito em relação direta com o estudo dos gêneros. Quando se faz passar um estilo de um gênero a outro, não somente se modifica a ressonância desse estilo de um gênero a outro, não somente se modifica a ressonância desse estilo como também se renova o gênero em questão (...). É ao nível do gênero que se registram e se estabilizam as novas formas de estruturação dos enunciados. 'Lá onde há estilo, há gênero' (AMORIM, 2004, p. 111).

Assim, Bakhtin ao retratar a questão do estudo da estilística (e claro, do enunciado) ou qualquer estudo que se faça a respeito da língua, põe em voga a necessidade de incluir o aprofundamento das modalidades dos gêneros, uma vez que eles configuram a língua viva, a linguagem em uso.

\section{Considerações finais}

Tendo em vista o diálogo que travamos ao longo deste artigo, observamos como Bakhtin é apresentado como um autor contemporâneo, que discordou da ideia de língua como um sistema estável, desprendido de valores ideológicos. Sua concepção de língua cinge a instância da interação, da dialética e é exibida como atividade social.

Nesse sentido, propõe o estudo do enunciado, tido como depende diretamente ao horizonte espacial e ideacional dos falantes, como modo de conferir ao enunciado o valor de elemento ideológico e comunicativo. Isso é nítido quando vimos o enunciado se diferindo das formas neutras da língua, como, por exemplo, da palavra e da oração, uma vez que convive com a alternância dos sujeitos do discurso, os quais ocupam determinadas posições no contexto real da enunciação, no cotidiano social. 
Assim, o enunciado tem uma extensão maior que a palavra (esta pensada como elemento linguístico) ou a oração, porque abarca elementos da situação extraverbal em paralelo com os da ordem linguística e enunciativa. Ao conceber a enunciação enquanto unidade da comunicação verbal, Bakhtin (2010) atesta que ela se constrói e assume uma forma fixa, particularmente no processo constituído por uma interação verbal específica, oriunda de um tipo de intercâmbio comunicativo social também específico. Logo, cada um desses tipos de intercâmbio comunicativo, pautados na alteridade discursiva, constrói, organiza e completa, ao seu modo, a forma gramatical e estilística da enunciação, promovendo distintas maneiras de dialogar.

Nessa tessitura, não poderíamos também nos esquecer da importância dos gêneros discursivos, pois são neles que os enunciados se materializam, se solidificam. Logo, uma vez que o estudo dos gêneros considera, sobretudo, "a natureza do enunciado" em sua diversidade e nos diferentes campos de atividade comunicacional, o meio propicia o surgimento de distintos gêneros e consolidifica a importância dada às esferas de atividades.

Assim, pautando-nos no que foi retratado ao longo deste trabalho, desejamos, por fim, a partir do diálogo estabelecido com o conceito de enunciado, apresentado sob um olhar alteritário do discurso, ressaltar a importância dos preceitos bakhtinianos para os estudos enunciativos.

\section{Referências bibliográficas:}

AMORIM, Marília. O pesquisador e seu outro. São Paulo: Musa, 2004.

BAKHTIN, Mikhail. Estética da criação verbal. São Paulo: Martins Fontes, 1997.

BAKHTIN, M.; VOLOSHINOV, V. N. Marxismo e filosofia da linguagem: problemas fundamentais do método sociológico da linguagem. São Paulo: Hucitec, 2006.

BAKHTIN, M. Para uma filosofia do ato responsável. Trad. Valdemir Miotello e Carlos Alberto Faraco. São Carlos: Pedro \& João Editores, 2010.

BRAIT, B. Bakhtin e a natureza constitutivamente dialógica da linguagem. In: BRAIT, B. (Org.). Bakhtin, dialogismo e construção de sentido. Campinas, SP: UNICAMP, 1997.

FIORIN, J. Luiz. Introdução ao pensamento de Bakhtin. São Paulo: Ática, 2006.

RODRIGUES, R. H. Os gêneros do discurso na perspectiva dialógica da linguagem: a abordagem de Bakhtin. In: MEURER, J. L.; BONINI, A.; MOTTA-ROTH, D. Gêneros: teorias, métodos e debates. São Paulo: Parábola Editorial, 2005. 


\title{
A look of otherness in Bakhtin: The study of the utterance as a form of dialogue
}

\begin{abstract}
Being the founding principle of the dialogic theory of discourse the philosophy of dialogue, which sees the man not as an individual but as one that is constituted through the dialogic relationship between an I and a you, every enunciation, according to this theoretical concept, becomes dialogic in nature. As the dialogism is considered the order of the enunciation, this does not close itself off, but is made through the endless dialogue between other enunciations that precede or succeed it in the discursive chain. Thus, based upon this otherness present in the discursive constitution, this paper aims, from a literary exhibition about the subject, discuss and reflect the bakhtinian precepts, taking in the concept of enunciation, anchored in speech genres, the genesis of an enunciation theory that, based on the enunciation of conditions and on the interlocutors involved, ensures the enunciation a historic univocally determined by the specific verbal interaction contexts. Therefore, Bakhtin's criticisms regarding the two central guidelines of philosophical-linguistic thinking, idealistic subjectivism and abstract objectivism are portrayed, as well as the differentiation between the concepts of "word" and "clause" to finally conduct a dialogue on the boundaries of the concrete utterance, which is seen as a key element of verbal communication.
\end{abstract}

Keywords: Enunciation. Dialogic theory of discourse. Bakhtin. Dialogism.

Recebido em: 20 de maio de 2015 .

Aprovado em: 14 de outubro de 2015. 